\section{Original Article}

\author{
Corresponding Author \\ Kern Singh \\ (D) https://orcid.org/0000-0002-6118-7273 \\ Department of Orthopaedic Surgery, Rush \\ University Medical Center, 1611 W. \\ Harrison St, Suite \#300, Chicago, IL 60612, \\ USA \\ Email: kern.singh@rushortho.com
}

Received: February 25, 2021

Revised: June 14, 2021

Accepted: June 20, 2021

\begin{abstract}
(c) (1) (2)
This is an Open Access article distributed under the terms of the Creative Commons Attribution Non-Commercial License (https://creativecommons.org/licenses/by-nc/4.0/) which permits unrestricted non-commercial use, distribution, and reproduction in any medium, provided the original work is properly cited.
\end{abstract}

Copyright $\odot 2022$ by the Korean Spinal Neurosurgery Society

\title{
Effects of Anterior Plating on Achieving Clinically Meaningful Improvement Following Single-Level Anterior Cervical Discectomy and Fusion
}

\author{
Conor P. Lynch, Elliot D.K. Cha, Madhav R. Patel, Caroline N. Jadczak, \\ Shruthi Mohan, Cara E. Geoghegan, Kern Singh
}

Department of Orthopaedic Surgery, Rush University Medical Center, Chicago, IL, USA

Objective: The clinical utility of anterior cervical plating for anterior cervical discectomy and fusion (ACDF) procedures remains controversial. This study aims to compare the impact of cervical plating on achievement of minimum clinically important difference (MCID) up to 2 years following ACDF.

Methods: Patients undergoing primary, single-level ACDF procedures were grouped based on whether their procedure included application of an anterior cervical plate. Demographics, preoperative spinal diagnoses, operative characteristics, and patient-reported outcome measures (PROMs) were compared between plating groups. Achievement of an MCID was assessed using the following previously established thresholds: 12-item Short Form health survey physical component summary (SF-12 PCS) 8.1, visual analogue scale (VAS) neck 2.6, VAS arm 4.1, Neck Disability Index (NDI) 8.5. Rates of MCID achievement were compared between groups.

Results: The cohort included 192 patients of whom 102 received plating and 90 received no plating. Plating status was significantly associated with Charlson Comorbidity Index and insurance status. Operative duration and estimated blood loss were significantly greater for the plating group. Both groups demonstrated significant improvements at the majority of postoperative timepoints. Significant intergroup differences in PROM improvement were demonstrated for VAS neck and NDI at 6 weeks. Rates of MCID achievement differed significantly between groups for NDI at 6 weeks, and 12 weeks, and SF-12 PCS overall.

Conclusion: Patients improved significantly in terms of pain, disability and physical function, regardless of plating status, and with the exception of early neck pain and disability, these improvements were similar between groups. Patients that underwent plating as part of their ACDF procedure achieved an MCID for physical function at lower rates overall.

Keywords: Cervical vertebrae, Spinal fusion, Visual analogue scale, Patient-reported outcome measures

\section{INTRODUCTION}

Anterior cervical discectomy and fusion (ACDF) is a commonly performed spinal procedure to treat cervical radiculopathy and myelopathy, with approximately 130,000 performed in the United States every year. ${ }^{1-3}$ The procedure itself provides significant benefits, with one study reporting $78 \%$ of patients were satisfied with their surgical outcomes. ${ }^{4}$ Part of the success associated with ACDF may be owed to substantial evolution in operative techniques since its introduction. While autografts alone were initially used to achieve fusion, use of metal plates and screws to decrease subsidence, and now the integration of titanium or polyether ether ketone interbody cages have contributed to continually effective treatment of cervical spine pathologies.

Plating has been utilized to strengthen the graft area, provide 
stability, and help maintain sagittal alignment; ${ }^{5}$ however, its benefits are still heavily debated due to associated complications such as esophageal irritation or damage, injury to vasculature, higher rates of adjacent segment disease (ASD), and dysphagia. ${ }^{6-8}$ In addition to soft tissue damage, challenges to the integrity of the plate instrumentation can occur with screw misalignment, plate loosening, or breakage causing subsequent damage to surrounding tissues. ${ }^{9}$

Although the stability added to the area of implantation by anterior plating may be advantageous, its associated complications may raise concerns when considering its use in addition to an interbody cage. With the rise of stand-alone cages that anchor directly into the vertebral bodies, the use of anterior plates has been further called into question. ACDF procedures using a stand-alone cage have demonstrated reduced rates of common postsurgical complications, such as dysphagia and ASD. ${ }^{10,11}$ Although use of stand-alone cages has become common practice for ACDF, this technique is not without its own reported disadvantages, such as increased subsidence, vertebral dislocation, and kyphosis. ${ }^{12}$

The currently available literature provides no clear consensus as to whether a stand-alone cage or a cage-plate combination is preferable, as compelling pros and cons have been presented for each and similar rates of fusion have been reported. ${ }^{8,11}$ One method that may aid in resolving this debate is the use of patient-reported outcome measures (PROMs) to quantify patient perceptions of health and functional status. A number of studies have explored the use of plates and stand-alone cages and their subsequent effects on PROMs but provide inconclusive evidence. For instance, studies focusing on perceptions of disability and pain have demonstrated no significant differences between ACDF procedures utilizing stand-alone cages vs. cages with anterior plating. ${ }^{13,8}$ Conversely, several investigators have reported outcomes that favor one technique over the other. ${ }^{13-15}$

Although the use of PROMs may offer a patient-centered perspective on key clinical symptoms, a simple comparison of their values fails to capture a change which patients perceive as a true clinical difference. More recent use of the minimum clinically important difference (MCID) may provide physicians with better insight into the true difference in postoperative symptoms. Defined as the smallest meaningful difference in scores that a patient perceives as beneficial, ${ }^{16}$ MCID is a useful metric with strong evidence as a predictor of patient satisfaction and functional clinical improvement following ACDF ${ }^{17,18}$ However, MCID achievement rates have yet to be empirically applied to the question of whether to include anterior plating with ACDF proce- dures. Therefore, this study endeavors to determine the impact of cervical plating on achievement of MCID up to 2 years following ACDF.

\section{MATERIALS AND METHODS}

\section{Patient Population}

Prior to study commencement, this study was approved by the Institutional Review Board of Rush University Medical Center (ORA \#14051301) and written informed consent were obtained from patients. A prospectively maintained surgical database was retrospectively reviewed for ACDF procedures from June 2005 to July 2020. Inclusion criteria were primary, singlelevel ACDF procedures for degenerative pathology. Exclusion criteria were patients without clear identification regarding the use of an anterior interbody plate, patients without preoperative PROM data, and patients undergoing surgery to treat traumatic, infectious, or malignant conditions. All procedures were performed by a single, fellowship-trained spine surgeon at the same academic institution. Anterior plate instrumentation consisted of low-profile titanium devices which were fixed to the anterior spine with 2 screws placed into the cranial and caudal vertebral bodies each. Stand-alone cage devices were composed of polyether ether ketone and were fixed to the superior and inferior endplates via one locking screw each.

\section{Data Collection}

Patient demographic information was collected which included age, gender, body mass index (BMI; categorized as nonobese: $\mathrm{BMI}<30 \mathrm{~kg} / \mathrm{m}^{2}$ and obese: BMI $\geq 30 \mathrm{~kg} / \mathrm{m}^{2}$ ), smoking status, diabetic status, American Society of Anesthesiologists classification (ASA; categorized as $\leq$ II and > II), Charlson Comorbidity Index score (CCI; categorized as $<1$ and $\geq 1$ ), ethnicity, and insurance/payment received. Pre-existing spinal pathologies and operative characteristics were recorded for all patients and included operative duration (from skin incision to skin closure, in minutes), estimated blood loss (EBL; in $\mathrm{mL}$ ), and postoperative length of stay (in hours). Rates of arthrodesis by the 1-year postoperative timepoint were confirmed using computed tomography (CT) scans of the lumbar spine. Additionally, preoperative and final postoperative lateral radiographs were reviewed and measured to determine global cervical lordosis, segmental lordosis, and cervical sagittal vertical axis (SVA) at the operated level. Rates of revision for clinically significant subsidence were also calculated for all patients. PROMs were administered at preoperative and postoperative ( 6 weeks, 12 weeks, 6 months, 1 year, 
2 years) timepoints and included 12-Item Short Form physical component summary (SF-12 PCS), visual analogue scale (VAS) for neck and arm pain, and Neck Disability Index (NDI).

\section{Statistical Analysis}

All statistical tests and calculations were performed using Stata IC 16.1 (StataCorp, College Station, TX, USA). Patients were sorted into 2 groups based on whether they had an anterior plate placed as part of their ACDF procedure. Demographic characteristics, pre-existing spinal pathologies, operative and radiographic variables were compared between groups using chi-square analysis and Student t-test for independent samples for categorical and continuous variables, respectively. Change in PROM scores $(\triangle \mathrm{PROM})$ was calculated as the difference of each postoperative score from preoperative baseline. A paired Student t-test compared postoperative to preoperative scores to assess improvement following ACDF. Student t-test for independent samples was used to assess differences in $\triangle \mathrm{PROM}$ between groups at each timepoint. Achievement of MCID was determined by comparing $\triangle \mathrm{PROM}$ values to the following previously established thresholds: SF-12 PCS (8.1), ${ }^{19}$ VAS arm (4.1), ${ }^{19}$ VAS neck (2.6) ${ }^{19} \mathrm{NDI}(8.5) .{ }^{19}$ Association of MCID achievement between groups was assessed using chi-square analysis at each postoperative timepoint and overall (whether MCID had been achieved at any timepoint). A p-value of $\leq 0.05$ was set as the threshold for statistical significance for all statistical tests.

\section{RESULTS}

A total of 192 patients were included, of whom 102 received anterior plating and 90 did not. The cohort's mean age was 47.4 years, $59.9 \%$ were male, and $48.4 \%$ were obese. Herniated nucleus pulposus was the most common preoperative spinal pathology. Mean operative duration was 53.2 minutes, mean EBL was $35.9 \mathrm{~mL}$, and mean length of stay was 19.0 hours. $\mathrm{CCI}(\mathrm{p}=$ $0.012)$ and insurance/payment collected $(p=0.027)$ were the only demographic characteristics significantly associated with plating status (Table 1). None of the included patients had a history of osteopenia or osteoporosis. None of the reported spinal pathologies were significantly associated with plating status. Operative duration (57.2 minutes vs. 48.8 minutes, $\mathrm{p}<0.001$ ) and EBL ( $40.2 \mathrm{~mL}$ vs. $31.1 \mathrm{~mL}, \mathrm{p}=0.001)$ were significantly greater for the plating group. None of the preoperative or postoperative sagittal alignment parameters differed between groups ( $p>0.050$, all). By 1 year postoperatively, radiographic evidence of arthrodesis was demonstrated in $98.4 \%$ of patients and did
Table 1. Patient demographics

\begin{tabular}{|c|c|c|c|}
\hline Demographic & $\begin{array}{c}\text { No plate } \\
(\mathrm{n}=90)\end{array}$ & $\begin{array}{c}\text { Plate } \\
(\mathrm{n}=102)\end{array}$ & p-value ${ }^{\dagger}$ \\
\hline Age (yr) & $45.6 \pm 8.5$ & $48.1 \pm 11.5$ & 0.312 \\
\hline Sex & & & 0.391 \\
\hline Female & $39(43.3)$ & $38(37.3)$ & \\
\hline Male & $51(56.7)$ & $64(62.8)$ & \\
\hline Body mass index $\left(\mathrm{kg} / \mathrm{m}^{2}\right)$ & & & 0.684 \\
\hline$<30$ & $45(50.0)$ & $54(52.9)$ & \\
\hline$\geq 30$ & $45(50.0)$ & $48(47.1)$ & \\
\hline Smoking status & & & 0.099 \\
\hline Nonsmoker & $78(86.7)$ & $79(77.5)$ & \\
\hline Smoker & $12(13.3)$ & $23(22.6)$ & \\
\hline Diabetes & & & 0.227 \\
\hline Diabetic & $6(6.7)$ & $12(11.8)$ & \\
\hline Nondiabetic & $84(93.3)$ & $90(88.2)$ & \\
\hline ASA PS classification & & & 0.508 \\
\hline$\leq \mathrm{II}$ & $66(73.3)$ & $79(77.5)$ & \\
\hline$>$ II & $24(26.7)$ & $23(22.6)$ & \\
\hline CCI score & & & $0.012^{*}$ \\
\hline$<1$ & $30(33.3)$ & $18(17.7)$ & \\
\hline$\geq 1$ & $60(66.7)$ & $84(82.4)$ & \\
\hline Ethnicity & & & 0.353 \\
\hline White & $63(70.0)$ & $76(74.5)$ & \\
\hline African-American & $12(13.3)$ & $14(13.7)$ & \\
\hline Hispanic & $7(7.8)$ & $7(6.9)$ & \\
\hline Asian & $1(1.1)$ & $3(2.9)$ & \\
\hline Other & $7(7.8)$ & $2(2.0)$ & \\
\hline Insurance & & & $0.027^{\star}$ \\
\hline Medicare/Medicaid & $3(3.3)$ & $13(12.8)$ & \\
\hline Workers' compensation & $27(30.0)$ & $36(35.3)$ & \\
\hline Private & $60(66.7)$ & $53(52.0)$ & \\
\hline
\end{tabular}

Values are presented as mean \pm standard deviation or number (\%). ASA PS, American Society of Anesthesiologists physical status; CCI, Charlson Comorbidity Index.

${ }^{*} \mathrm{p}<0.05$, statistically significant differences. ${ }^{\dagger} \mathrm{p}$-values calculated using an unpaired t-test or chi-square test to determine differences between groups.

not vary significantly between groups. All 3 patients ( 2 plate, 1 no plate) who failed to demonstrate arthrodesis underwent revision fusion procedures at the index level. Sufficient follow-up data to assess fusion status was unavailable for 7 patients (Table 2). Clinically significant subsidence was not observed among any of the patients in either group.

Significant postoperative improvements were demonstrated 
Table 2. Perioperative characteristics

\begin{tabular}{|c|c|c|c|}
\hline Characteristic & $\begin{array}{l}\text { No plate } \\
(\mathrm{n}=90)\end{array}$ & $\begin{array}{c}\text { Plate } \\
(\mathrm{n}=102)\end{array}$ & $\mathrm{p}$-value ${ }^{\dagger}$ \\
\hline \multicolumn{4}{|l|}{ Spinal pathology } \\
\hline Degenerative disc disease & $5(5.6)$ & $2(2.0)$ & 0.185 \\
\hline Central stenosis & $24(26.7)$ & $32(31.4)$ & 0.474 \\
\hline Radiculopathy & $20(22.2)$ & $19(18.6)$ & 0.537 \\
\hline Myelopathy & $2(2.2)$ & $1(1.0)$ & 0.489 \\
\hline Myeloradiculopathy & $67(74.4)$ & $76(74.5)$ & 0.992 \\
\hline Herniated nucleus pulposus & $84(93.3)$ & $95(93.1)$ & 0.957 \\
\hline Operative time (min) & $48.8 \pm 11.1$ & $57.2 \pm 13.4$ & $<0.001^{\star}$ \\
\hline Estimated blood loss (mL) & $31.1 \pm 12.0$ & $40.2 \pm 21.7$ & $0.001^{\star}$ \\
\hline Length of stay (hr) & $17.9 \pm 15.1$ & $20.1 \pm 22.0$ & 0.431 \\
\hline Arthrodesis ${ }^{\ddagger}$ & $85(98.8)$ & $97(98.0)$ & 0.645 \\
\hline \multicolumn{4}{|l|}{ Cervical lordosis $\left(^{\circ}\right)$} \\
\hline Preoperative & $8.4 \pm 6.0$ & $9.5 \pm 7.2$ & 0.385 \\
\hline Postoperative & $10.5 \pm 6.9$ & $10.8 \pm 8.8$ & 0.828 \\
\hline Change & $2.1 \pm 6.5$ & $1.3 \pm 7.3$ & 0.547 \\
\hline \multicolumn{4}{|l|}{ Segmental lordosis $\left({ }^{\circ}\right)$} \\
\hline Preoperative & $3.9 \pm 2.6$ & $4.1 \pm 3.9$ & 0.704 \\
\hline Postoperative & $4.9 \pm 3.8$ & $6.2 \pm 4.5$ & 0.083 \\
\hline Change & $1.0 \pm 5.0$ & $2.2 \pm 5.5$ & 0.227 \\
\hline \multicolumn{4}{|c|}{ Cervical sagittal vertical axis $(\mathrm{mm})$} \\
\hline Preoperative & $26.9 \pm 9.1$ & $28.0 \pm 11.1$ & 0.605 \\
\hline Postoperative & $27.7 \pm 9.7$ & $28.7 \pm 9.4$ & 0.568 \\
\hline Change & $0.7 \pm 6.9$ & $0.8 \pm 6.7$ & 0.978 \\
\hline
\end{tabular}

Values are presented as number (\%) or mean \pm standard deviation. ${ }^{*} \mathrm{p}<0.05$, statistically significant differences. ${ }^{\dagger} \mathrm{p}$-values calculated using an unpaired t-test or chi-square test to determine differences between groups. "Insufficient follow-up data was available to determine fusion status for 7 patients.

in both groups for all PROMs at all timepoints ( $\mathrm{p} \leq 0.030)$, except SF-12 PCS at 2 years $(\mathrm{p}=0.100)$ for the no plating group and SF-12 PCS, and NDI at 6 weeks $(\mathrm{p}=0.358, \mathrm{p}=0.066)$, VAS arm at 1 year $(\mathrm{p}=0.145)$, and VAS neck, VAS arm, and NDI at 2 years $(\mathrm{p}=0.347, \mathrm{p}=0.576, \mathrm{p}=0.058)$ for the plating group (Table 3). $\triangle \mathrm{PROM}$ was significantly lower in the plating group for VAS neck (1.9 vs. $3.1, \mathrm{p}=0.018$ ) and NDI (5.0 vs. $13.6, \mathrm{p}=$ $0.010)$ at 6 weeks only. No other significant intergroup differences in $\triangle \mathrm{PROM}$ were observed. A majority of patients achieved an overall MCID for all measures, except for SF-12 PCS in the plating group (41.0\%). Achievement of MCID varied significantly by group for NDI at 6 weeks ( $37.3 \%$ vs. $58.9 \%, p=0.025)$ and 12 weeks ( $72.6 \%$ vs. $48.9 \%, \mathrm{p}=0.017$ ), and SF-12 PCS overall $(41.0 \%$ vs. $59.7 \%, \mathrm{p}=0.022)$ (Table 4$)$.

\section{DISCUSSION}

Following the introduction of stand-alone interbody cages, the utility of anterior plating for ACDF procedures remains controversial. While satisfactory outcomes have been achieved with both techniques, plating has been associated with increased incidence of dysphagia and ASD, while greater rates of subsidence and less restoration of cervical lordosis have been reported with stand-alone cages. ${ }^{8,11,20}$ Previous studies examining PROMs are similarly inconclusive regarding the advantage of one technique over the other. ${ }^{8,13,20,21}$ The present study seeks to address this ongoing controversy through the lens of MCID in PROMs for pain, disability, and physical function.

$\mathrm{CCI}$ and insurance status differed significantly between groups. The plating group had a higher proportion of patients with a CCI score of 1 or greater, indicating that more of these patients had some medical comorbidity. Narain et al. ${ }^{22}$ previously demonstrated that ACDF patients with a CCI of 2 or greater are less likely to achieve MCID in NDI than those with lower comorbidity burden. While we chose to assess a lower comorbidity threshold ( $<1$ vs. $\geq 1$ ), it is possible that the difference in comorbidity burden between groups may have affected our results. Additionally, a larger proportion of the plating group consisted of patients with workers' compensation or Medicare/Medicaid payments. A retrospective analysis by Goldberg et al. ${ }^{23} \mathrm{re}-$ ported no significant differences in long-term, patient-reported functional outcomes between workers' compensation and nonworkers' compensation patients following ACDF. Therefore, this difference in workers' compensation status is unlikely to represent a significant confounder in the present study.

Prevalence of preoperative spinal pathologies did not significantly vary between groups. Operative duration was significantly longer and EBL was significantly greater for the plating group than the no plating group. Similar operative findings have been reported by previous studies. ${ }^{11,14}$ A systematic review of ACDF with stand-alone cage vs traditional cage and plate techniques by Cheung et al. ${ }^{8}$ demonstrated that on average, ACDF procedures without use of an anterior plate were associated with 9.90 $\mathrm{mL}$ less blood loss $(\mathrm{p}<0.01)$ than those with a plate. Vaishnav et al. ${ }^{14}$ also reported significantly shorter operative time for cageonly procedures. Interestingly, although they did not demonstrate a direct association of dysphagia with plating, they did demonstrate that increased operative time was correlated with rates of postoperative dysphagia, a complication that has been reported in association with anterior plating by several other studies. ${ }^{11,20,21}$ While the observed difference in blood loss was 
Table 3. PROM improvement following ACDF

\begin{tabular}{|c|c|c|c|c|c|c|c|}
\hline \multirow{2}{*}{ Variable } & \multicolumn{3}{|c|}{ No plate } & \multicolumn{3}{|c|}{ Plate } & \multirow{2}{*}{ p-value } \\
\hline & Mean \pm SD & $\triangle \mathrm{PROM}$ & p-value ${ }^{\dagger}$ & Mean \pm SD & $\triangle \mathrm{PROM}$ & p-value ${ }^{\dagger}$ & \\
\hline \multicolumn{8}{|l|}{ SF-12 PCS } \\
\hline Preoperative & $36.1 \pm 8.7$ & - & - & $39.6 \pm 9.8$ & - & - & - \\
\hline 6 Weeks & $38.2 \pm 8.8$ & $3.6 \pm 8.6$ & $0.014^{\star}$ & $38.8 \pm 10.6$ & $1.3 \pm 9.9$ & 0.358 & 0.254 \\
\hline 12 Weeks & $42.6 \pm 8.7$ & $5.9 \pm 8.1$ & $<0.001^{\star}$ & $45.0 \pm 10.5$ & $4.3 \pm 7.7$ & $<0.001^{\star}$ & 0.287 \\
\hline 6 Months & $42.7 \pm 10.1$ & $8.5 \pm 11.0$ & $<0.001^{\star}$ & $41.4 \pm 9.4$ & $6.4 \pm 9.2$ & $0.002^{\star}$ & 0.421 \\
\hline 1 Year & $43.1 \pm 10.9$ & $8.2 \pm 12.6$ & $0.004^{\star}$ & $43.7 \pm 10.3$ & $4.6 \pm 6.4$ & $0.004^{*}$ & 0.255 \\
\hline 2 Years & $41.7 \pm 19.3$ & $6.6 \pm 14.4$ & 0.100 & $46.0 \pm 11.5$ & $6.5 \pm 8.3$ & $0.027^{\star}$ & 0.988 \\
\hline \multicolumn{8}{|l|}{ VAS neck } \\
\hline Preoperative & $6.5 \pm 2.2$ & - & - & $5.9 \pm 2.4$ & - & - & - \\
\hline 6 Weeks & $3.2 \pm 2.4$ & $3.1 \pm 2.3$ & $<0.001^{\star}$ & $3.9 \pm 2.7$ & $1.9 \pm 3.1$ & $<0.001^{\star}$ & $0.018^{*}$ \\
\hline 12 Weeks & $3.0 \pm 2.5$ & $3.4 \pm 2.5$ & $<0.001^{\star}$ & $3.0 \pm 2.5$ & $2.9 \pm 3.0$ & $<0.001^{\star}$ & 0.348 \\
\hline 6 Months & $3.0 \pm 2.8$ & $3.5 \pm 2.8$ & $<0.001^{\star}$ & $2.6 \pm 2.5$ & $3.2 \pm 3.2$ & $<0.001^{\star}$ & 0.687 \\
\hline 1 Year & $3.1 \pm 2.6$ & $2.9 \pm 3.0$ & $<0.001^{\star}$ & $3.9 \pm 3.0$ & $1.9 \pm 3.6$ & $0.025^{\star}$ & 0.258 \\
\hline 2 Years & $4.1 \pm 2.4$ & $2.7 \pm 2.3$ & $0.001^{\star}$ & $4.8 \pm 3.6$ & $1.5 \pm 4.5$ & 0.347 & 0.421 \\
\hline \multicolumn{8}{|l|}{ VAS arm } \\
\hline Preoperative & $6.0 \pm 2.6$ & - & - & $6.2 \pm 2.5$ & - & - & - \\
\hline 6 Weeks & $1.9 \pm 2.1$ & $3.8 \pm 2.8$ & $<0.001^{\star}$ & $3.3 \pm 2.8$ & $2.7 \pm 3.5$ & $<0.001^{\star}$ & 0.081 \\
\hline 12 Weeks & $2.4 \pm 2.6$ & $3.4 \pm 3.0$ & $<0.001^{\star}$ & $3.1 \pm 3.2$ & $3.1 \pm 3.8$ & $<0.001^{\star}$ & 0.684 \\
\hline 6 Months & $2.2 \pm 2.6$ & $3.4 \pm 3.1$ & $<0.001^{\star}$ & $3.3 \pm 3.2$ & $2.8 \pm 3.4$ & $<0.001^{\star}$ & 0.358 \\
\hline 1 Year & $2.8 \pm 2.9$ & $2.5 \pm 3.4$ & $<0.001^{\star}$ & $4.7 \pm 3.0$ & $1.5 \pm 4.5$ & 0.145 & 0.374 \\
\hline 2 Years & $4.0 \pm 3.0$ & $2.0 \pm 2.2$ & $0.003^{*}$ & $3.3 \pm 4.1$ & $1.2 \pm 5.5$ & 0.576 & 0.642 \\
\hline \multicolumn{8}{|l|}{ NDI } \\
\hline Preoperative & $44.8 \pm 19.9$ & - & - & $39.1 \pm 17.7$ & - & - & - \\
\hline 6 Weeks & $29.3 \pm 18.7$ & $13.6 \pm 14.7$ & $<0.001^{\star}$ & $33.2 \pm 21.3$ & $5.0 \pm 19.0$ & 0.066 & $0.010^{*}$ \\
\hline 12 Weeks & $27.3 \pm 20.9$ & $17.0 \pm 15.0$ & $<0.001^{\star}$ & $27.6 \pm 20.5$ & $12.1 \pm 21.6$ & $<0.001^{\star}$ & 0.198 \\
\hline 6 Months & $22.9 \pm 20.9$ & $21.6 \pm 18.2$ & $<0.001^{\star}$ & $24.5 \pm 22.6$ & $15.7 \pm 22.1$ & $<0.001^{\star}$ & 0.177 \\
\hline 1 Year & $26.2 \pm 21.5$ & $16.3 \pm 19.2$ & $<0.001^{\star}$ & $21.7 \pm 20.0$ & $15.3 \pm 22.9$ & $0.012^{\star}$ & 0.866 \\
\hline 2 Years & $28.7 \pm 21.4$ & $13.1 \pm 14.9$ & $0.004^{*}$ & $21.6 \pm 19.2$ & $21.6 \pm 24.4$ & 0.058 & 0.323 \\
\hline
\end{tabular}

PROM, patient-reported outcome measure; ACDF, anterior cervical discectomy and fusion; SD, standard deviation; SF-12 PCS, 12 -item Short Form health survey physical component summary; VAS, visual analogue scale; NDI, Neck Disability Index.

${ }^{*} \mathrm{p}<0.05$, statistically significant differences. ${ }^{\dagger} \mathrm{p}$-values calculated using a paired t-test to assess within-group improvement from preoperative baseline. ${ }^{*}$ p-values calculated using a t-test for independent samples to assess intergroup differences in PROM score improvement $(\triangle \mathrm{PROM})$.

statistically significant, we agree with other authors that such a relatively small difference is unlikely to be clinically relevant. ${ }^{8}$ However, the increased operative duration associated with anterior plating may be cause for slightly more concern. Any amount of time under general anesthesia is not without risk. If this time can be minimized through the use of a stand-alone cage, this should be carefully considered in preoperative planning.

While some have suggested that anterior plating may lend additional stability to the operative segment, we were unable to detect a significant difference in fusion rates between the 2 groups. These results are largely in line with previous literature which similarly reports satisfactory rates of arthrodesis regardless of plating status. ${ }^{8,11}$ Preoperatively, neither segmental nor global sagittal alignment significantly differed between groups, which confirms that preoperative kyphosis is unlikely to represent a significant source of bias in our study. Postoperatively, neither mean angles nor pre-post change significantly differed for segmental nor global cervical lordosis measurements. These find- 
Table 4. MCID achievement rates

\begin{tabular}{|c|c|c|c|}
\hline Variable & No plate & Plate & p-value ${ }^{\dagger}$ \\
\hline \multicolumn{4}{|l|}{ SF-12 PCS } \\
\hline 6 Weeks & $13(33.3)$ & $13(25.0)$ & 0.384 \\
\hline 12 Weeks & $18(40.0)$ & $23(33.8)$ & 0.504 \\
\hline 6 Months & $17(44.7)$ & $11(42.3)$ & 0.847 \\
\hline 1 Year & $11(45.8)$ & $4(20.0)$ & 0.072 \\
\hline 2 Years & $7(46.7)$ & $4(36.4)$ & 0.599 \\
\hline Overall & $40(59.7)$ & $34(41)$ & $0.022^{\star}$ \\
\hline \multicolumn{4}{|l|}{ VAS neck } \\
\hline 6 Weeks & $33(53.2)$ & $23(41.1)$ & 0.187 \\
\hline 12 Weeks & $40(67.8)$ & $27(52.9)$ & 0.111 \\
\hline 6 Months & $31(58.5)$ & $29(61.7)$ & 0.744 \\
\hline 1 Year & $14(41.2)$ & $9(42.9)$ & 0.902 \\
\hline 2 Years & $5(33.3)$ & $4(44.4)$ & 0.586 \\
\hline Overall & $53(76.8)$ & $40(65.6)$ & 0.156 \\
\hline \multicolumn{4}{|l|}{ VAS arm } \\
\hline 6 Weeks & $26(45.6)$ & $21(40.4)$ & 0.582 \\
\hline 12 Weeks & $21(41.2)$ & $20(40.8)$ & 0.971 \\
\hline 6 Months & $19(38.8)$ & $19(44.2)$ & 0.599 \\
\hline 1 Year & $9(26.5)$ & $6(30.0)$ & 0.780 \\
\hline 2 Years & $3(20.0)$ & $2(28.6)$ & 0.655 \\
\hline Overall & $36(57.1)$ & $33(57.9)$ & 0.934 \\
\hline \multicolumn{4}{|l|}{ NDI } \\
\hline 6 Weeks & $33(58.9)$ & $19(37.3)$ & $0.025^{\star}$ \\
\hline 12 Weeks & $37(72.6)$ & $23(48.9)$ & $0.017^{\star}$ \\
\hline 6 Months & $33(68.8)$ & $26(65.0)$ & 0.709 \\
\hline 1 Year & 17 (51.5) & 10 (55.6) & 0.782 \\
\hline 2 Years & $9(60.0)$ & $4(57.1)$ & 0.899 \\
\hline Overall & $51(82.3)$ & $36(66.7)$ & 0.053 \\
\hline
\end{tabular}

Values are presented as number (\%).

MCID, minimum clinically important difference; SF-12 PCS, 12-item Short Form health survey physical component summary; VAS, visual analogue scale; NDI, Neck Disability Index.

${ }^{*} \mathrm{p}<0.05$, statistically significant differences. ${ }^{\dagger} \mathrm{p}$-values calculated using a chi-square test to assess MCID achievement between groups.

ings are in agreement with 2 previous meta-analyses which demonstrated nonsignificant change in segmental or global cervical sagittal alignment. ${ }^{8,21}$ Additionally, we detected no significant difference in change of SVA between groups. Effects of anterior plating on postoperative sagittal alignment may be more dramatic for procedures that include multiple spinal levels. For example, in a study of 2-level ACDF, Kwon et al. ${ }^{12}$ demonstrated significantly greater increase in cervical lordosis and greater decrease in SVA for patients receiving anterior plates compared to stand-alone cages. Therefore, biomechanical change may be a more important factor in the decision to utilize anterior plating with more extensive procedures, but may not be the most important deciding factor for single-level fusions. Results of previous studies regarding risk of implant subsidence are mixed, with Cheung et al. ${ }^{8}$ reporting increased rates associated with standalone cages and Nambiar et al. ${ }^{21}$ reporting no significant difference between groups. In the present study, no cases of frank subsidence were observed among patients in either group, suggesting an agreement with Nambiar et al.s result. This agreement may be related to the single-level nature of both the current study and those included in Nambiar et al's systematic review.

Our analysis revealed early (6 weeks) differences between groups in terms of postoperative improvements in VAS neck and NDI, with the plating group demonstrating significantly less improvement in both metrics. One possible explanation for these short-term differences could be related to longer time to recover due to the additional operative trauma of anterior plating, which involves additional instrumentation and may require a larger operative window. However, no significant long-term differences in "raw" improvement scores were observed. While mean change scores in NDI, VAS neck, and SF-12 PCS did demonstrate several points of difference at some longitudinal timepoints, the high degree of variability observed in these scores likely contributed to the nonsignificant intergroup difference observed for these measures. Results of previous studies regarding pain and disability outcomes based on the use of anterior plating have been mixed. Etemadifar et al. ${ }^{15}$ and Kim et al. ${ }^{24}$ both observed a significant difference in postoperative NDI, favoring the cage-only technique. Additionally, Oliver et al..$^{13}$ and Vaishnav et al. ${ }^{14}$ demonstrated more favorable VAS neck outcomes for patients who received anterior plating. Interestingly, Oliver et al..$^{13}$ also demonstrated more favorable long-term VAS arm outcomes for patients that did not undergo anterior plating. However, a number of other studies have demonstrated no significant differences in terms of VAS arm, VAS neck, and NDI at short- or long-term follow-up between patients undergoing ACDF with and without anterior plating. ${ }^{8,11,21,25}$

It should be noted that previous studies have primarily compared mean PROM scores between groups, while we compared the magnitude of change in these scores. Our method may allow for more relevant comparison by better accounting for preoperative PROM scores. Furthermore, while a multitude of previous studies have assessed the association of anterior plating with VAS and NDI, few if any have explored physical function 
outcomes. Our analysis of PROM values did not demonstrate significant differences between groups in either short- or longterm improvement in the included physical function measure.

While a number of comparisons have been made in terms of "raw" PROM values, the lack of reported data regarding rates of clinically meaningful improvement represents a substantial shortcoming of the available literature regarding the use of anterior plating in ACDF procedures. In line with our findings regarding $\triangle \mathrm{PROM}$, plating was associated with lower rates of shortterm MCID achievement in NDI. However, the more favorable $\triangle$ PROM findings in VAS neck were not similarly borne out in our MCID analysis.

Overall, a greater proportion of patients in the no plating group achieved an MCID in SF-12 PCS. Evidence for mechanical/structural benefits of one technique over the other have been relatively consistent but cite pros and cons for each. Although decreased segmental range of motion is often to be desired following fusion procedures, perhaps the increased neck stiffness reported to be associated with plating ${ }^{26}$ might hamper the physical capabilities of some patients. Additionally, several previous studies have demonstrated increased rates of ASD associated with anterior plating. ${ }^{8,20}$ It is possible that early symptoms of such degeneration at adjacent disc levels could explain some of the observed differences in physical function improvement.

While our study is the first to assess the impact of anterior plating on MCID achievement, it is subject to several notable limitations. Our assessment relied heavily on data obtained from self-reported questionnaires, which are inherently vulnerable to bias. Since our express purpose was to quantify results in terms of patient perceptions, some such bias was likely unavoidable. Additionally, all ACDF procedures were performed by a single experienced spine surgeon at a single academic institution, which may limit the generalizability of our results. Despite these limitations, the present study utilizes a robust sample size, includes longitudinal follow-up data (through 2 years postoperatively), and is the first to include an analysis of MCID achievement to assess ACDF outcomes based on the use or exclusion of anterior plating.

\section{CONCLUSION}

Patients generally demonstrated favorable outcomes and significant improvements in PROM following ACDF, regardless of whether their procedure included anterior plating. In terms of mean PROM score improvement, only short-term neck pain and disability were less favorable for the plating group. Rates of
MCID achievement were likewise generally similar for ACDF procedures involving both techniques, and a majority of patients in both groups met these thresholds for neck pain, arm pain, and disability. Clinically meaningful improvements in early (6 weeks, 12 weeks) disability and overall physical function were more common amongst the cage-only group. While the use of anterior plating has both pros and cons for patients undergoing ACDF, clinically important improvements in disability and physical function may be more likely without the use of a plate.

\section{NOTES}

Conflict of Interest: The authors have nothing to disclose. Funding/Support: This study received no specific grant from any funding agency in the public, commercial, or not-for-profit sectors.

Author Contribution: Conceptualization: CL, EC, KS; Data curation: CL, SM, CG, KS; Formal analysis: CL, EC; Methodology: CL, EC; Project administration: CL, SM, CG; Writing - original draft: CL, EC, CJ; Writing - review \& editing: CL, EC, CJ, SM, CG, KS.

\section{ORCID}

Conor P. Lynch: 0000-0002-9554-2878

Elliot D.K. Cha: 0000-0001-8118-008X

Kern Singh: 0000-0002-6118-7273

\section{REFERENCES}

1. Yue WM, Brodner W, Highland TR. Long-term results after anterior cervical discectomy and fusion with allograft and plating: a 5- to 11-year radiologic and clinical follow-up study. Spine (Phila Pa 1976) 2005;30:2138-44.

2. Matz PG, Holly LT, Groff MW, et al. Indications for anterior cervical decompression for the treatment of cervical degenerative radiculopathy. J Neurosurg Spine 2009;11:174-82.

3. Saifi C, Fein AW, Cazzulino A, et al. Trends in resource utilization and rate of cervical disc arthroplasty and anterior cervical discectomy and fusion throughout the United States from 2006 to 2013. Spine J 2018;18:1022-9.

4. Cauthen JC, Kinard RE, Vogler JB, et al. Outcome analysis of noninstrumented anterior cervical discectomy and interbody fusion in 348 patients. Spine (Phila Pa 1976) 1998;23: 188-92.

5. Song KJ, Choi BY. Current concepts of anterior cervical discectomy and fusion: a review of literature. Asian Spine J 2014; 
8:531-9.

6. Wang Z, Jiang W, Li X, et al. The application of zero-profile anchored spacer in anterior cervical discectomy and fusion. Eur Spine J 2015;24:148-54.

7. Chen Y, Chen H, Wu X, et al. Comparative analysis of clinical outcomes between zero-profile implant and cages with plate fixation in treating multilevel cervical spondilotic myelopathy: a three-year follow-up. Clin Neurol Neurosurg 2016;144:72-6.

8. Cheung ZB, Gidumal S, White S, et al. Comparison of anterior cervical discectomy and fusion with a stand-alone interbody cage versus a conventional cage-plate technique: a systematic review and meta-analysis. Global Spine J 2019;9: 446-55.

9. Viswanathan VK, Manoharan SR. To plate or not to plate after a single- or two-level anterior cervical discectomy: fusion with cage-plate construct or stand-alone cage. Asian Spine J 2017;11:1-3.

10. Overley SC, Merrill RK, Leven DM, et al. A matched cohort analysis comparing stand-alone cages and anterior cervical plates used for anterior cervical discectomy and fusion. Global Spine J 2017;7:394-9.

11. Zhou J, Li J, Lin H, et al. A comparison of a self-locking standalone cage and anterior cervical plate for ACDF: Minimum 3 -year assessment of radiographic and clinical outcomes. Clin Neurol Neurosurg 2018;170:73-8.

12. Kwon WK, Kim PS, Ahn SY, et al. Analysis of associating factors with C2-7 sagittal vertical axis after two-level anterior cervical fusion: comparison between plate augmentation and stand-alone cages. Spine (Phila Pa 1976) 2017;42:31825.

13. Oliver JD, Goncalves S, Kerezoudis P, et al. Comparison of outcomes for anterior cervical discectomy and fusion with and without anterior plate fixation: a systematic review and meta-analysis. Spine (Phila Pa 1976) 2018;43:E413-22.

14. Vaishnav AS, Saville P, McAnany S, et al. Predictive factors of postoperative dysphagia in single-level anterior cervical discectomy and fusion. Spine (Phila Pa 1976) 2019;44:E400-7.

15. Etemadifar M, Andalib A, Shafiee H, et al. Comparison of the outcomes of cage-stand-alone with cage-with-plate fixation in one level and two levels for treating cervical disk diseases. J Craniovertebr Junction Spine 2018;9:170-4.

16. Brozek JL, Guyatt GH, Schünemann HJ. How a well-ground- ed minimal important difference can enhance transparency of labelling claims and improve interpretation of a patient reported outcome measure. Health Qual Life Outcomes 2006; 4:69.

17. Chotai S, Sivaganesan A, Parker SL, et al. Patient-specific factors associated with dissatisfaction after elective surgery for degenerative spine diseases. Neurosurgery 2015;77:15763.

18. Andresen AK, Paulsen RT, Busch F, et al. Patient-reported outcomes and patient-reported satisfaction after surgical treatment for cervical radiculopathy. Global Spine J 2018;8: 703-8.

19. Parker SL, Godil SS, Shau DN, et al. Assessment of the minimum clinically important difference in pain, disability, and quality of life after anterior cervical discectomy and fusion: clinical article. J Neurosurg Spine 2013;18:154-60.

20. Yang Z, Zhao Y, Luo J. Incidence of dysphagia of zero-profile spacer versus cage-plate after anterior cervical discectomy and fusion: a meta-analysis. Medicine (Baltimore) 2019; 98:e15767.

21. Nambiar M, Phan K, Cunningham JE, et al. Locking standalone cages versus anterior plate constructs in single-level fusion for degenerative cervical disease: a systematic review and meta-analysis. Eur Spine J 2017;26:2258-66.

22. Narain AS, Hijji FY, Khechen B, et al. Risk factors associated with failure to reach minimal clinically important difference in patient-reported outcomes following anterior cervical discectomy and fusion. Int J Spine Surg 2019;13:262-9.

23. Goldberg EJ, Singh K, Van U, et al. Comparing outcomes of anterior cervical discectomy and fusion in workman's versus non-workman's compensation population. Spine J 2002;2: 408-14.

24. Kim SY, Yoon SH, Kim D, et al. A prospective study with cage-only or cage-with-plate fixation in anterior cervical discectomy and interbody fusion of one and two levels. J Korean Neurosurg Soc 2017;60:691-700.

25. Tabaraee E, Ahn J, Bohl DD, et al. Comparison of surgical outcomes, narcotics utilization, and costs after an anterior cervical discectomy and fusion: stand-alone cage versus anterior plating. Clin Spine Surg 2017;30:E1201-5.

26. Shimamoto N, Cunningham BW, Dmitriev AE, et al. Biomechanical evaluation of stand-alone interbody fusion cages in the cervical spine. Spine (Phila Pa 1976) 2001;26:E432-6. 